\title{
Clinical swallowing assessment in the diagnosis of silent aspiration
}

\author{
Mariana Zerbetto Fabricio ${ }^{1}$ \\ https://orcid.org/0000-0001-7414-1234 \\ Aline Cristina Pacheco-Castilho' \\ https://orcid.org/0000-0003-2927-2766 \\ Octavio Marques Pontes-Neto' \\ https://orcid.org/0000-0003-0317-843X \\ Roberto Oliveira Dantas ${ }^{1}$ \\ https://orcid.org/0000-0003-2183-0815
}

Universidade de São Paulo, Faculdade de Medicina de Ribeirão Preto - FMRPUSP, Ribeirão Preto, São Paulo, Brasil.

Conflict of interests: Nonexistent

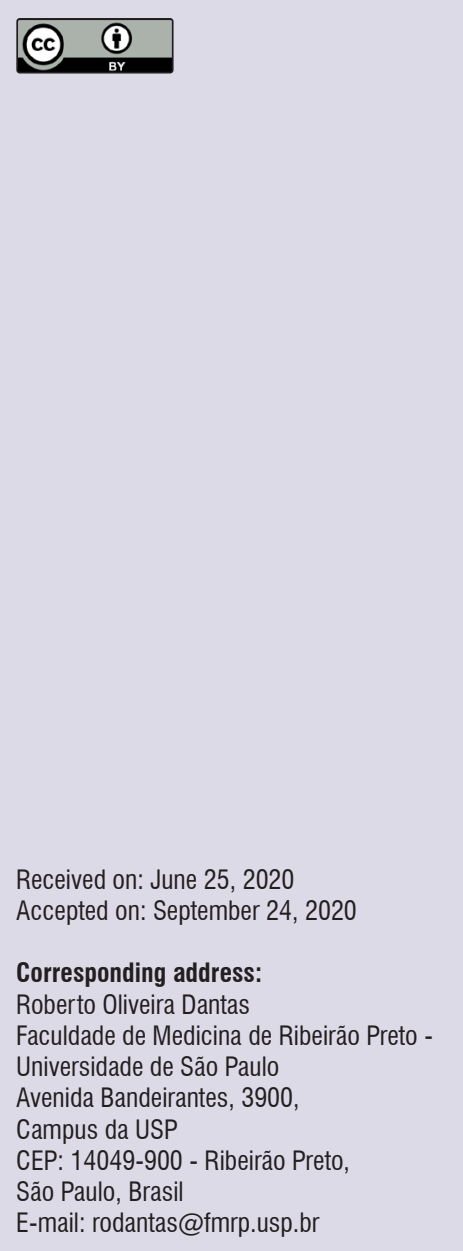

\section{ABSTRACT}

Purpose: to identify, in the clinical assessment of swallowing, signs indicating silent aspiration in ischemic stroke patients.

Methods: forty-six patients were assessed, 17 days being the mean time elapsed from the stroke to the swallowing assessment. The clinical assessment encompassed structural and functional aspects, oximetry monitoring, and cervical auscultation. During the videofluoroscopy examination, the patients were also monitored with pulse oximetry. In both assessments, the patients were given $100 \mathrm{ml}$ of liquid. In the statistical analysis, the exact logistic regression test and odds ratio calculation were used, with a 0.05 significance level.

Results: seven, out of the 46 patients, presented aspiration, which was silent in six of them. Change in the cervical auscultation, in the clinical assessment (OR: 18.8; 95\% Cl: 1.2 - 1000, $p=0.03$ ), was associated with silent aspiration, as detected in the videofluoroscopy. The hawking present in the analysis of the recording (OR: 12.2; $95 \% \mathrm{Cl}: 1.23-\infty, p=0.03$ ), was associated with possible non-silent laryngotracheal penetrations and aspirations. No change was identified regarding oxygen saturation in patients presented with silent aspiration.

Conclusion: the change in cervical auscultation observed in the clinical assessment can indicate silent aspiration in patients affected by an ischemic stroke.

Keywords: Stroke; Deglutition Disorders; Deglutition; Pneumonia, Aspiration 


\section{INTRODUCTION}

One of the main causes of post-stroke death is aspiration pneumonia ${ }^{1-3}$. The risk of dysphagic patients to develop pneumonia is eight times greater ${ }^{4}$; in those with airway aspiration, such risk increases to 11 times $^{5}$. When the aspiration is silent, with no reaction on the part of the patient, the risk increases to 13 times $^{6}$.

Silent aspiration is defined as the entrance of gastric or oropharyngeal material below the vocal folds without coughing, choking, or any sign that indicates the occurrence of aspiration ${ }^{7,8}$ It is present in 15 to $39 \%$ of the subacute stroke patients and 2 to $25 \%$ of the acute stroke patients ${ }^{9}$.

Different methods are used to assess the risk of aspiration, such as clinical assessment, scintigraphy, and videofluoroscopic swallowing study (VFSS), of which the last one is considered the best method to diagnose silent aspiration. However, a large number of speech-language-hearing services and professionals do not have a device available to perform videofluoroscopy, and the patients are not always in clinical conditions to undergo the exam, resulting in difficulties to reach a reliable diagnosis.

The greatest concern of professionals who attend patients with complaints of dysphagia is the difficulty to diagnose aspiration in a clinical assessment. They worry about taking quick and precise measures regarding the feeding route of each patient when such information is lacking.

This study aimed to identify signs in the clinical assessment of swallowing that indicate silent aspiration, with the hypothesis that the clinical assessment of ischemic stroke patients is changed when silent aspiration occurs.

\section{METHODS}

This study design was observational and prospective. The research was conducted at the Hospital das Clínicas da Faculdade de Medicina de Ribeirão Preto - USP, in the Department of Radiology, between August 2015 and July 2017. Patients that had been admitted to the Emergency Room of the Hospital das Clínicas da Faculdade de Medicina de Ribeirão Preto, Universidade de São Paulo (HCFMRP-USP), diagnosed with ischemic stroke, were invited to participate in the research after hospital discharge. The study was approved by the Research Ethics Committee of the Hospital das Clínicas and Faculdade de Medicina de Ribeirão Preto, São Paulo, Brazil, under process no. 14962/2014.

Patients with ischemic stroke older than 18 years participated in the study. The inclusion criteria were: neurological diagnosis of ischemic stroke, confirmed with neuroimage examination, in clinical conditions to undergo the assessments, and agreeing to participate in the study. Patients with a neurological diagnosis other than ischemic stroke, not in clinical conditions to undergo the assessments, and who did not agree to participate were excluded from the research. The patients who agreed to participate in the research signed the informed consent form, after reading it and having their questions answered.

Initially, the collection encompassed identification data, date of the ischemic stroke, date of hospitalization, date of hospital discharge, and feeding (whether oral feeding or via nasogastric tube, as well as limitations related to the food consistency). The assessments and their analyses were conducted by two speech therapists with experience in the field; each of them did not know the results of the assessment carried out by the other professional. One was responsible for the clinical assessment and clinical analysis of the recording, and the other, for the VFSS.

The assessments in this study were separated into three stages:

\section{Clinical assessment:}

Previously described assessment protocol $^{10}$, conducted in two stages.

- Structural assessment (without food): lip sensitivity (right and left side, upper and lower lips) and tongue sensitivity (right and left side, tip and dorsum) were observed; the patient was asked to do the following movements to assess the mobility of the phono-articulatory organs: lip closure for three seconds, protruding and retracting the tongue, inside touching by the tongue to the right and left, inflating the cheeks (right, left, both, and alternated), insufflating the cheeks. Also, the laryngeal elevation was observed (when swallowing saliva).

- Functional assessment: in which $100 \mathrm{ml}$ of liquid consistency (water) was given in a cup.

The patients were instructed to drink the liquid spontaneously (i.e., without a verbal command to swallow). Some drank the liquid in sequential sips, others in fractioned sips. Clinical signs were observed and taken note of, including anterior oral escape, oral residue (rest of the consistency observed in the 
oral cavity with direct inspection), hawking, wet voice (observed with the production of the prolonged "a" vowel after swallowing the volume), coughing, choking, watering eye, respiratory changes, and cervical auscultation changes (presence of or increase in noise). In the cervical auscultation assessment ${ }^{11}$, the stethoscope used was the Littmann Cardiology III. The auscultation was performed on the lateral region of the trachea, above the cricoid cartilage.

\section{Videofluoroscopy of swallowing}

Following the clinical examination, the VFSS was performed by a radiology technician and a speechlanguage-hearing therapist in an X-ray room with an Arcomax angiography machine, manufactured by Philips, model BV300. The images were recorded 30 frames per second. The individuals were seated, and the focus of the fluoroscopic image was defined anteriorly on the lips, superiorly on the hard palate, posteriorly on the spine, and inferiorly on the airway and proximal esophagus on the level of the seventh cervical vertebra ${ }^{12}$.

A cup with $100 \mathrm{ml}$ of liquid consistency $(67 \mathrm{ml}$ of water and $33 \mathrm{ml}$ of barium sulfate at $100 \%$ ) was given to the patient. The swallowing instructions were the same as the clinical assessment. The parameters observed in the VFSS were the anterior and posterior extra-oral escape, oral control (subjective), bolus preparation, bolus transportation, oral residue, beginning of swallowing, and pharyngeal residue. The Rosenbek scale was used to classify laryngotracheal penetration or aspiration, as well as silent aspiration ${ }^{13}$. The images generated in VFSS were recorded in DVD for later analysis.

In the clinical assessment and VFSS, the patients were monitored with pulse oximetry, measured in the right index finger, using a Contec oximeter, model CMS50D. The result was considered abnormal when there was a variation $\geq 3 \%$ in the oxygen saturation after swallowing water, considering the values taken immediately before swallowing and the lowest ones taken in the 60 seconds after swallowing.

\section{Clinical analysis of the recording}

While the patients were undergoing the VFSS, a Nikon camera 42x Wide Optical Zoom ED VR 4.3-180 $\mathrm{mm}$ 1:3-5.9 fixed on a WT 3710 tripod was positioned in front of them to record the head and chest images.
The same speech-language-hearing therapist that conducted both the structural and functional clinical assessments of swallowing observed the patient's images, taken with the camera while they were undergoing the VFSS, and analyzed their signs suggestive of dysphagia. This analysis was named in this study as the clinical analysis of the recording.

The signs observed were the anterior extra-oral escape, oral residue (rest of consistency in the oral cavity), hawking, wet voice (observed with the production of the prolonged "a" vowel), coughing, choking, watering eye, and respiratory change.

The cervical auscultation was not conducted simultaneously with the recording, as the presence of the stethoscope would interfere with the visualization of the VFSS.

A comparison was made between the clinical assessment of swallowing (before the VFSS), the VFSS, and the clinical assessment of the recording (analysis of the signs suggestive of dysphagia at the moment of the VFSS).

The participants were divided into three groups, considering the Rosenbek classification ${ }^{13}$ for penetration/aspiration in the VFSS:

- Group 1: participants classified with a score of 1 and 2

- Group 2: participants classified with a score of 3 to 6

- Group 3: participants classified with a score of 8

No patient was classified with a score of 7 .

The results were analyzed based on two comparisons. The first one, between the three groups, individually, and the second, between group 1 and groups 2 and 3 combined. Thus, the group with little or no change in the Rosenbek scale (Group 1) was compared with the one in higher degrees of the scale (Group 2), and the one with silent aspiration (Group 3). The patients in Group 1 were also compared with those in Groups 2 and 3 together to assess the patients with little changes in the Rosenbek scale with those with more important changes.

\section{Statistical analysis}

Descriptive statistics of absolute and relative frequencies were used to describe the categorical variables.

The exact logistic regression method was used to compare the groups regarding the variables of interest, calculating the corresponding odds ratio (OR). All the comparisons were controlled for sex and age. All 
the analyses were performed aided by the SAS 9.2 software, with the significance level set at $p \leq 0.05$.

\section{RESULTS}

A total of 50 adult patients participated in this study. One of them was excluded due to incomplete examination, and three for being diagnosed with hemorrhagic stroke. Hence, 46 post-ischemic stroke adult individuals were analyzed - 17 women (37\%) and 29 men (63\%), 33 in Group 1 (Rosenbek 1 and 2), seven in Group 2 (Rosenbek 3 to 6), and six in Group 3 (Rosenbek 8).

The patients' mean age was $66.5 \pm 13.6$ years, with limits of 22 and 91 years. The mean length of hospital stay was $5.3 \pm 4.5$ days, which ranged from one to 19 days. The time elapsed from the disease onset to the assessment ranged from six to 35 days, with a mean of $17.3 \pm 6.7$ days. As for feeding, 45 (98\%) were exclusively on oral feeding, of which 34 (74\%) were already on an unrestricted diet. Of the other patients, 11 (26\%) had creamy, soft solid, and thick liquid diets. One patient $(2 \%)$ had nasogastric intubation and partially received oral feeding.

In the clinical examination, cheek mobility change was observed, as well as the presence of hawking in the analysis of the recording in Group 2. Change in cervical auscultation was observed in the clinical assessment in half of the patients with silent aspiration detected in the VFSS (Group 3).

The distribution of mobility, tonicity, and sensitivity of the phono-articulatory organs in the structural assessment can be observed in Table 1. The same assessment was performed in all the patients, and no significant changes were observed in most of the cases. The greatest percentage of change occurred in movements related to cheek mobility.

Table 1. Results of the assessments of mobility, tonicity, and sensitivity of the phono-articulatory organs in the ischemic stroke patients assessed $(n=46)$

\begin{tabular}{lcccc}
\hline & Normal & \multicolumn{2}{c}{ Changed } \\
\cline { 2 - 4 } & N & $\%$ & N & $\%$ \\
\hline Lips & 45 & 97.8 & 1 & 2.1 \\
Retraction for 3 seconds & 44 & 95.6 & 2 & 4.3 \\
Sensitivity in the upper R & 45 & 97.8 & 1 & 2.1 \\
Sensitivity in the upper L & 44 & 95.6 & 2 & 4.3 \\
Sensitivity in the lower R & 44 & 95.6 & 2 & 4.3 \\
Sensitivity in the lower L & & & & \\
\hline Tongue & 41 & 89.1 & 5 & 10.8 \\
Protraction & 38 & 82.6 & 8 & 17.6 \\
Retraction & 35 & 76 & 11 & 23.9 \\
Alternated protraction/retraction & 40 & 86.9 & 6 & 13 \\
Touch inner R cheek & 40 & 86.9 & 6 & 13 \\
Touch inner L cheek & 39 & 84.7 & 7 & 15.2 \\
Alternated touching R/L cheeks & 42 & 91.3 & 4 & 8.6 \\
Sensitivity to the R & 42 & 91.3 & 4 & 8.6 \\
Sensitivity to the L & 40 & 86.9 & 6 & 13 \\
Sensitivity on the tip & 42 & 91.3 & 4 & 8.6 \\
Sensitivity on the dorsum & & & & \\
\hline Cheeks & 32 & 69.5 & 14 & 30.4 \\
Inflation & 25 & 54.3 & 21 & 45.6 \\
Inflation of the R side & 25 & 54.3 & 21 & 45.6 \\
Inflation of the L side & 25 & 21 & 45.6 \\
Alternated inflation R and L & 54.3 & 20 & 43.4 \\
Insufflation & 26 & 56.5 & 4 & 8.6 \\
Laryngeal elevation & 42 & 91.3 & &
\end{tabular}

Captions: R: right; L: left; N: number 
Changes in swallowing were observed in the clinical assessment in $50 \%$ of the patients, in the analysis of the recording in $45.6 \%$, and in the VFSS in $41.3 \%$ of them. Laryngotracheal aspiration was observed in the VFSS in seven (15.2\%) participants, and six of them presented silent aspiration.

The results of the comparison between the three groups are shown in Table 2. It was observed that three patients $(50 \%)$ with silent aspiration in Group 3 had changes in cervical auscultation in the clinical assessment (OR: 18.8; 95\% Cl: 1.2-1000; $\mathrm{p}=0.03$ ). Another datum found was the presence of hawking in the clinical analysis of the recording made during the VFSS (OR: $12.2 ; 95 \% \mathrm{Cl}: 1.23-\infty ; \mathrm{p}=0.03$ ) in Group 2. The $\infty$ symbol indicates a remarkably high value. Hawking was present in 3 (43\%) out of the seven participants in this Group. The limits in the $95 \%$ confidence interval varied greatly, which does not allow for safe conclusions regarding difference to Group 1.

Table 2. Comparison of cervical auscultation in the clinical examination with hawking in the recording between the three groups. Number and (percentage)

\begin{tabular}{|c|c|c|c|c|c|c|c|}
\hline \multirow{2}{*}{ Group } & \multicolumn{3}{|c|}{ Change in Cervical Auscultation - Clinical } & \multirow[b]{2}{*}{ Odds ratio } & \multirow{2}{*}{\multicolumn{2}{|c|}{$95 \% \mathrm{Cl}$}} & \multirow[b]{2}{*}{ p-value } \\
\hline & 0 & 1 & Total & & & & \\
\hline Group 1 & $32(97)$ & $1(3)$ & 33 & 1.0 & & & \\
\hline Group 2 & $5(71)$ & $2(29)$ & 7 & 10.9 & 0.4 & 854.8 & 0.21 \\
\hline Group 3 & $3(50)$ & $3(50)$ & 6 & 18.8 & 1.2 & 1000 & 0.03 \\
\hline Total & 40 & 6 & 46 & & & & \\
\hline \multirow{2}{*}{ Group } & \multicolumn{3}{|c|}{ Hawking - Recording } & & \multirow{2}{*}{\multicolumn{2}{|c|}{$95 \% \mathrm{Cl}$}} & \\
\hline & 0 & 1 & Total & Odds ratio & & & p-value \\
\hline Group 1 & $32(97)$ & $1(3)$ & 33 & 1.0 & & & \\
\hline Group 2 & $4(57)$ & $3(43)$ & 7 & 12.2 & 1.23 & $\infty$ & 0.03 \\
\hline Group 3 & $5(83)$ & $1(17)$ & 6 & 5.7 & 0.06 & 548.3 & 0.63 \\
\hline Total & 41 & 5 & 46 & & & & \\
\hline
\end{tabular}

Captions: 0 : absence; 1 : presence; $\infty$ : a remarkably high numerical value

Exact logistic regression test and odds ratio calculation

Cl- Confidence Interval

The anterior oral escape, oral control, bolus preparation and transportation, oral residue, beginning of swallowing, pharyngeal residue, wet voice, coughing, choking, watering eye, multiple swallowing, and respiratory changes were not included in the table as there was no statistically significant difference between the groups for these parameters.

The comparison of Group 1 with Groups 2 and 3 (combined) is seen in Table 3. It is observed in it that hawking is more frequently present, according to the clinical analysis of the recording made during the VFSS, in patients with more impaired swallowing
(OR: $12.9 ; 95 \% \mathrm{Cl}: 1.02-689.11 ; \mathrm{p}=0.04)$. The other clinical signs were not included in the table because they did not present any statistically significant difference in the comparison of Groups 2 and 3 with Group 1.

No decrease in oxygen saturation $\geq 3 \%$ of the basal values was observed in any of the six participants with silent aspiration. Among the patients without silent aspiration $(n=40)$, a decrease in oxygen saturation $\geq 3 \%$ was observed in two $(5 \%)$ of them in the clinical assessment, and in four (10\%) in the assessment of the recording. 
Table 3. Comparison of the occurrence of hawking and coughing observed in the recording between Group 1 and Groups 2 and 3 (combined). Number and (percentage)

\begin{tabular}{|c|c|c|c|c|c|c|c|}
\hline \multirow{2}{*}{ Group } & \multicolumn{3}{|c|}{ Hawking - Recording } & \multirow[b]{2}{*}{ Odds ratio } & \multirow{2}{*}{\multicolumn{2}{|c|}{$95 \% \mathrm{CI}$}} & \multirow{2}{*}{ p-value } \\
\hline & 0 & 1 & Total & & & & \\
\hline Group 1 & $32(97)$ & $1(3)$ & 33 & 1.00 & & & \\
\hline Groups 2 and 3 & $9(69)$ & $4(31)$ & 13 & 12.86 & 1.01 & 689.11 & 0.04 \\
\hline Total & 41 & 5 & 46 & & & & \\
\hline \multirow{2}{*}{ Group } & \multicolumn{3}{|c|}{ Coughing - Recording } & & \multirow{2}{*}{\multicolumn{2}{|c|}{$95 \% \mathrm{Cl}$}} & \\
\hline & 0 & 1 & Total & Udds ratio & & & p-value \\
\hline Group 1 & $33(100)$ & $0(0)$ & 33 & 1.00 & & & \\
\hline Groups 2 and 3 & $9(69)$ & $4(31)$ & 13 & 9.27 & 0.91 & & 0.06 \\
\hline Total & 42 & 4 & 46 & & & & \\
\hline
\end{tabular}

Captions: 0: absence; 1 : presence; $\infty$ : a remarkably high numerical value

Exact logistic regression test and odds ratio calculation

$\mathrm{Cl}$ - Confidence Interval

\section{DISCUSSION}

The authors report that the function of the cheek is related to oral hygiene, ejection, chewing, and articulation ${ }^{14}$, while others report the importance of the mobility of the phono-articulatory organs to exert pressure on the bolus and eject $i^{14}$. Swallowing is a sequence; therefore, changes in the oral phase can result in changes in the pharyngeal phase. The low intraoral pressurization combined with the difficulty to eject the bolus can result in oral and pharyngeal residue ${ }^{15}$. In patients with preserved sensitivity, the presence of hawking is an attempt to clear the pharyngeal region from some material after stasis or laryngeal penetration of creamy or liquid food ${ }^{16}$.

There are divergences in the literature regarding the usefulness of cervical auscultation in the investigation of laryngotracheal penetration and aspiration. The reason is that it is a subjective analysis that requires that the people involved in the examination be trained; also, no agreement has been established between investigators ${ }^{17,18}$. Nevertheless, when performed by professionals trained in the method, its sensitivity is $94 \%$, and the specificity, $70 \%$ to detect penetration/aspiration defined in the videofluoroscopy ${ }^{17}$. Others defend its use as a complementary method in clinical assessment ${ }^{19,20}$.

It is recommended that cervical auscultation be used, combined with other assessment methods, to detect aspiration, either silent or not. The agreement between cervical auscultation and silent aspiration in half of the cases is an important datum for professionals that work in centers where no objective instruments are available to help reach a diagnosis of this complication, as well as in the case of patients that are not clinically stable to undergo an objective examination. As professional experience increases, the number of false negatives should decrease; thus, cervical auscultation must be always performed. It is not a perfect method, but it is the best one available for this diagnosis among professionals who cannot resort to VFSS.

Pulse oximetry was not efficient to diagnose aspiration, as already demonstrated in previous papers, and must not be used with this purpose ${ }^{21}$.

This study has some limitations concerning the individuals assessed. The number of patients with silent aspiration in the VFSS was relatively low, which explains the great difference in the limits of the confidence interval. This fact can be associated with the clinical condition of the patients at the moment of the assessment since most of them were in the subacute phase of stroke, whereas the greatest prevalence of silent aspiration takes place in the acute phase and more serious clinical conditions. The liquids taken in the clinical assessment and VFSS were not the same. In the clinical assessment, it was pure water, whereas, in the VFSS, barium sulfate had been added. Modifications in the liquid taken by the patient change the results of the VFSS ${ }^{22}$. Nonetheless, the two liquids have the same level (level 0 - liquid) in the classification and terminology of the International Dysphagia Diet Standardization Initiative (IDDSI) ${ }^{23}$ - hence, any difference regarding aspiration was quite unlikely to happen.

Observing the patients in the recording made during the VFSS, no simultaneous signs were found in the recording and VFSS that indicated a diagnosis of silent aspiration. The change in the cervical auscultation 
detected in the clinical assessment was the sign that most associated with the occurrence of silent aspiration in the VFSS, though observed in only half of the cases. With improved training and experience in the method, it will perhaps be possible to diagnose silent aspiration in a larger number of cases, a hypothesis that demands further research.

\section{CONCLUSION}

In patients with no reaction when aspiring liquid material into their airways, the change in cervical auscultation was the most frequent sign indicating silent aspiration. However, the absence of change in the auscultation does not exclude the occurrence of aspiration.

\section{REFERENCES}

1. Pacheco-Castilho AC, Vanin GM, Dantas RO, Pontes-Neto OM, Martino R. Dysphagia and associated pneumonia in stroke patients from Brazil: a systematic review. Dysphagia. 2019;34(4):499-520.

2. Paixão $C T$, Silva LD, Camerini FG. Perfil da disfagia após um acidente vascular cerebral: Uma revisão integrativa. Rev Rene Fortaleza. 2010;11(1):181-90.

3. Cohen DL, Roffe C, Beavan J, Blackett B, Fairfield $\mathrm{CA}$, Hamdy $\mathrm{S}$ et al. Post-stroke dysphagia: a review and design considerations for future trials. Int $\mathrm{J}$ Stroke. 2016;11(4):399-411.

4. Eltringham SA, Kilner K, Gee M, Karen S, Bray BD, Pownall $S$ et al. Impact of dysphagia assessment and management on risk of stroke-associated pneumonia: a systematic review. Cerebrovasc Dis. 2018;46(3-4):97-105.

5. Martino R, Foley $\mathrm{N}$, Bhogal $\mathrm{S}$, Diamant $\mathrm{N}$, Speechley M, Teasell R. Dysphagia after stroke: incidence, diagnosis and pulmonary complications. Stroke. 2005;36(12):2756-63.

6. Pikus L, Levine MS, Yang Y, Rubesin SE, Katzka DA, Laufer I et al. Videofluoroscopic studies of swallowing dysfunction and the relative risk of pneumonia. Am J Roentgenol. 2003;180(6):1613-6.

7. Marik PE. Aspiration pneumonitis and aspiration pneumonia. N Engl J Med. 2001;344(9):665-71.

8. Bretan O. Quando suspeitar de aspiração silenciosa? Rev Assoc Med Bras. 2007;53(4):283-92.
9. Ramsey DJC, Smithard DG, Kalra L. Silent aspiration: what do we know? Dysphagia. 2005;20(3):218-25.

10. Padovani AR, Moraes DP, Mangili LD, Andrade CRF. Protocolo de avaliação de risco para disfagia (PARD). Rev Soc Bras Fonoaudiol. 2007;12(3):199-205.

11. Cardoso MCAF, Gomes DH. Ausculta cervical em adultos sem queixas de alteração na deglutição. Arq Int Otorrinolaringol. 2010;14(4):404-9.

12. Barros APB, Carrara-de-Angelis E. Videofluoroscopia da deglutição orofaríngea. In: Jotz GP, Carrara-de-Angelis E, Barros APB (orgs). Tratado da deglutição e disfagia no adulto e na criança. Rio de Janeiro: Revinter, 2009. p.84-8.

13. Rosenbek JC, Robins JA, Roecker EB, Coyle $\mathrm{JL}$, Wood JL. A penetration aspiration scale. Dysphagia. 1996;11(2):93-8.

14. Jotz GP, Dornelles S. Fisiologia da deglutição. In: Jotz GP, Carrara-de-Angelis E, Barros APB (orgs). Tratado da deglutição e disfagia no adulto e na criança. Rio de Janeiro: Revinter, 2009. p. 16-20.

15. Xerez DR, Carvalho YSV, Costa MMB. Estudo clínico e videofluoroscópico da disfagia na fase subaguda do acidente vascular encefálico. Radiol Bras. 2004;37(1):9-14.

16. Mourão LF, Xavier DAN, Neri AL, Luchesi KF. Association study between natural chronic diseases of aging and swallowing changes referred by community elderly. Audiol. Commun. Res. 2016;21:e1657.

17. Cardoso MCAF, Fontoura EG. Valor da ausculta cervical em pacientes acometidos por disfagia neurogênica. Arq Int Otorrinolaringol. 2009;13(4):431-9.

18. Borr G, Hielscher-Fastabend M, Lucking A. Rehability and validity of cervical auscultation. Dysphagia. 2007;22(3):225-34.

19. Bolzan GP, Christmann MK, Berwing LC, Costa CC, Rocha RM. Contribution of the cervical auscultation in clinical assessment of the oropharyngeal dysphagia. Rev. CEFAC. 2013;15(2):455-65.

20. Ferrucci JL, Mangilli LD, Sassi FC, Limongi SCO, Andrade CRF. Sons da deglutição na prática fonoaudiológica: análise crítica da literatura. Einstein. 2013;11(4):535-9.

21. Britton D, Roeske A, Ennis SK, Benditt JO, Quinn C, Graville D. Utility of pulse oximetry to detect aspiration: an evidence-based systematic review. Dysphagia. 2018;33(3):282-92. 
22. Stokely SL, Molfenter SM, Steele CM. Effects of barium concentration on oropharyngeal swallow timing measures. Dysphagia. 2014;29(1):78-82.

23. Cichero JA, Lam P, Steele CM, Hanson B, Chen $\mathrm{J}$, Dantas RO et al. Development of international terminology and definitions for texture-modified foods and thickened fluids used in dysphagia management: the IDDSI framework. Dysphagia. 2017;32(2):293-314. 